08,09

\title{
Фотолюминесценция центров окраски германий-вакансия в полученных химическим газофазным осаждением алмазных частицах
}

\author{
(C) С.А. Грудинкин ${ }^{1}$, Н.А. Феоктистов ${ }^{1}$, К.В. Богданов ${ }^{2}$, А.В. Баранов ${ }^{2}$, В.Г. Голубев ${ }^{1}$ \\ ${ }^{1}$ Физико-технический институт им. А.Ф. Иофрфе РАН, \\ Санкт-Петербург, Россия \\ ${ }^{2}$ Национальный исследовательский университет ИТМО, \\ Санкт-Петербург, Россия \\ E-mail: grudink.gvg@mail.ioffe.ru
}

Поступила в Редакцию 27 декабря 2019 г.

В окончательной редакции 27 декабря 2019 г.

Принята к публикации 27 декабря 2019 г.

\begin{abstract}
Методом химического газофазного осаждения с горячей нитью на подложке германия синтезированы алмазные частицы с центрами окраски германий-вакансия. Формирование центров окраски происходило в процессе роста алмазных частиц за счет введения атомов германия, образовавшихся в результате травления пластины кристаллического германия атомарным водородом. Рассмотрены условия процесса осаждения из газовой фазы, влияющие на фотолюминесценцию центров окраски германий-вакансия в алмазных частицах. Наибольшая интенсивность фотолюминесценции центров окраски германий-вакансия достигнута для алмазных частиц, полученных на подложке при температуре ее поверхности близкой к температуре плавления германия. В спектрах фотолюминесценции алмазных частиц также наблюдались линии, предположительно связанные с оптическими центрами, в состав которых входит вольфрам.
\end{abstract}

Ключевые слова: алмаз, германий, центры окраски, фотолюминесценция, химическое газофазное осаждение

DOI: $10.21883 /$ FTT.2020.05.49253.665

\section{1. Введение}

Оптически активные центры окраски в алмазе, представляющие собой примесно-вакансионные комплексы, обладают большими перспективами применения в квантовой информатике, биомедицине, магнитометрии, термометрии [1-5]. Алмазы обладают исключительной твердостью, высокой химической стойкостью, биосовместимостью, а центры окраски в них характеризуются высокой фотостабильностью. Для создания однофотонных источников излучения, люминесцентных биомаркеров и термометрии высокого разрешения требуются центры окраски с интенсивной и узкой бесфононной линией (БФЛ) фотолюминесценции (ФЛ), низкой спектральной диффузией БФЛ [6]. Перечисленным требованиям удовлетворяют центры окраски, включающие междоузельный атом IV группы ( $\mathrm{Si}, \mathrm{Ge}, \mathrm{Sn}$ и $\mathrm{Pb})$ и две ближайших вакансии в соседних узлах решетки [7]. Наиболее изученным представителем этого семейства центров является центр окраски кремний-вакансия (SiV) в отрицательном зарядовом состоянии. Из-за слабого электрон-фононного взаимодействия примерно 70\% интенсивности ФЛ центра сосредоточено в узкой БФЛ с максимумом на длине волны $738 \mathrm{~nm}$ (полная ширина линии на половине высоты (FWHM) при комнатной температуре составляет $0.7 \mathrm{~nm}$ для одиночных центров $\mathrm{SiV}$ [8] и 4-9 nm для ансамбля центров $\mathrm{SiV}[9,10])$. Центр обладает инверсной симметрией, что обуславливает низкую спектральную диффузию БФЛ [11].

В последнее время значительные усилия сосредоточены на исследовании центра окраски германий-вакансия $(\mathrm{GeV})$ в отрицательном зарядовом состоянии. Этот центр имеет схожую с центром $\mathrm{SiV}$ структуру. В работе [12] показано, что центр $\mathrm{GeV}$ имеет более высокую, чем центр $\mathrm{SiV}$ квантовую эффективность ФЛ. Это определяет его преимущество при использовании в качестве эмиттера для квантовой нанофотоники. Увеличение квантовой эффективности способствует повышению температурного и пространственного разрешения в нанотермометрии [13].

В центрах окраски $\mathrm{GeV}$ и $\mathrm{SiV}$ спин-орбитальное взаимодействие приводит к расщеплению основного $\left({ }^{2} E_{g}\right)$ и возбужденного $\left({ }^{2} E_{u}\right)$ состояний на два состояния (тонкая структура центра) [7]. Значение величины расщепления основного состояния центра $\mathrm{GeV}(150 \mathrm{GHz})$ выше, чем центра $\mathrm{SiV}(47 \mathrm{GHz})$, что обуславливает большее время спиновой когерентности [14]. В спектре ФЛ центра $\mathrm{GeV}$ при комнатной температуре БФЛ, в которой сосредоточено $60 \%$ интенсивности излучения [15], имеет максимум на длине волны $\sim 602 \mathrm{~nm}$ и характерное время жизни $\sim 1.4 \mathrm{~ns}[16]$. При комнатной температуре FWHM БФЛ центра GeV в спектре ФЛ гомоэпитаксиальной алмазной пленки составляет $\sim 4.6 \mathrm{~nm}[17]$. 
Одним из способов введения центров $\mathrm{GeV}$ в алмаз является метод ионной имплантации $[12,16]$. К недостаткам метода ионной имплантации относится отсутствие возможности обеспечить глубокое проникновение примеси и введение высоких концентраций примеси. Неизбежны также радиационные повреждения структуры поверхности алмаза, например, образование межузельных атомов углерода и вакансий, от которых не удается полностью избавиться в процессе последующего отжига $[16,18]$. Алмазные частицы с высоким совершенством кристаллической структуры и интенсивной линией ФЛ центра $\mathrm{GeV}$ были получены в условиях высокого давления и высоких температур (НРНT) [15,19,20].

Для получения алмазных пленок и частиц с центрами окраски широко используется метод химического газофазного осаждения (CVD). Это, в первую очередь, связано с возможностью контролируемого введения центров окраски [17,21]. К другим важным достоинствам различных модификаций метода CVD относятся: варьирование толщины алмазных пленок и размера алмазных частиц (от нескольких десятков нанометров до сотен микрон), осаждение алмаза на неалмазных подложках сложной формы, возможность изменения параметров синтеза в процессе роста и in-situ оптический контроль размера алмазных частиц. Поэтому, получение методом CVD алмазных частиц с введенными в них в процессе роста центрами окраски $\mathrm{GeV}$ представляет несомненный интерес.

Целью настоящей работы являлось получение на подложке германия методом химического газофазного осаждения с горячей нитью (Hot Filament Chemical Vapor Deposition - HFCVD) алмазных частиц с интенсивной фотолюминесценцией центров окраски $\mathrm{GeV}$. Источником атомов германия были радикалы $\mathrm{GeH}_{x}$, образовавшиеся в результате травления кристаллического германия атомарным водородом. В работе проведен поиск условий проведения CVD процесса с целью достижения максимальной интенсивности БФЛ центров окраски $\mathrm{GeV}$ в спектрах ФЛ алмазных частиц.

\section{2. Методика эксперимента}

Алмазные частицы синтезированы методом HFCVD. Параметры технологического процесса HFCVD: температура вольфрамовой спирали - 2000-2200 ${ }^{\circ} \mathrm{C}$, рабочее давление в реакторе - 40 Torr, расход водорода $500 \mathrm{sccm}$, концентрация метана — $2 \%$, время роста алмазных частиц $-2 \mathrm{~h}$.

В качестве центров зародышеобразования использовались наноалмазы детонационного синтеза с характерным размером $\sim 4 \mathrm{~nm}$, которые контролируемо наносились на кремниевую подложку методом аэрозольного распыления [22]. Концентрация наноалмазов детонационного синтеза на поверхности подложки составляла $\sim 10^{6} \mathrm{~cm}^{-2}$. Размер синтезированных алмазных частиц, измеренный методом атомно-силовой микроскопии, варьировался в диапазоне от 0.6 до $1 \mu \mathrm{m}$.

Измерения спектров комбинационного рассеяния света (КРС) и ФЛ проводились в геометрии „обратного рассеяния“ с помощью микро-рамановского спектрометра Renishaw InVia Raman Microscope, оснащенного конфокальным микроскопом. Спектральное разрешение спектрометра составляло $\sim 1 \mathrm{~cm}^{-1}$. При измерениях использовалась длина волны возбуждающего излучения $488 \mathrm{~nm}$. Для измерений, проводимых при комнатной температуре, излучение возбуждающего лазера фокусировалось объективом $100 \times(\mathrm{NA}=0.9)$ в пятно на образце диаметром $\sim 1 \mu \mathrm{m}$. Спектры КРС и ФЛ при $T=80 \mathrm{~K}$ измерены с использованием криогенной установки Linkam THMS 600. Для фокусировки падающего пучка на образец использовался объектив $50 \times(\mathrm{NA}=0.50)$ с большим рабочим расстоянием.

\section{3. Экспериментальные результаты и их обсуждение}

Для введения центров $\mathrm{GeV}$ необходимо обеспечить доставку атомов $\mathrm{Ge}$ на поверхность алмазных частиц в процессе их синтеза. В настоящей работе твердотельным источником атомов $\mathrm{Ge}$ являлась полированная подложка кристаллического германия толщиной $300 \mu \mathrm{m}$, на которую осаждались алмазные частицы. В некоторых синтезах в алмазную кристаллическую решетку одновременно с центрами $\mathrm{GeV}$ вводились центры $\mathrm{SiV}$. Для этого на держателе подложек рядом с подложкой германия располагалась пластина кристаллического кремния.

Твердотельные источники кремния (пластины $\mathrm{Si}$ ) широко используются для введения центров окраски $\mathrm{SiV}$ в процессе CVD синтеза [9,10,23,24]. Травление атомарным водородом кремний содержащих пластин приводит к появлению летучих радикалов $\mathrm{SiH}_{x}$. Перенос и осаждение этих радикалов на поверхность растущих алмазных кристаллитов с последующим вхождением кремния в решетку алмаза обуславливает образование центров $\mathrm{SiV}$. Можно предположить, что образование центров $\mathrm{GeV}$ в процессе CVD синтеза при использовании твердотельных источников германия происходит по механизму схожему с механизмом формирования центров окраски $\mathrm{SiV}$. Источником атомов $\mathrm{Ge}$ в алмазной решетке являются радикалы $\mathrm{GeH}_{x}$, образованные в результате травления атомарным водородом кристаллического германия [25]. Также возможен вклад от атомов $\mathrm{Ge}$, образующихся в результате испарения с поверхности кристаллического германия.

Спектры ФЛ синтезированных алмазных частиц, полученные при температуре подложки германия $830^{\circ} \mathrm{C}$, представлены на рис. 1. Интенсивности спектров ФЛ нормированы на интенсивность линии $521.9 \mathrm{~nm}$, обусловленной КРС на ТО-фононе $\left(\sim 1332 \mathrm{~cm}^{-1}\right)$ в кристаллической решетке алмаза. В спектрах наблюдается 


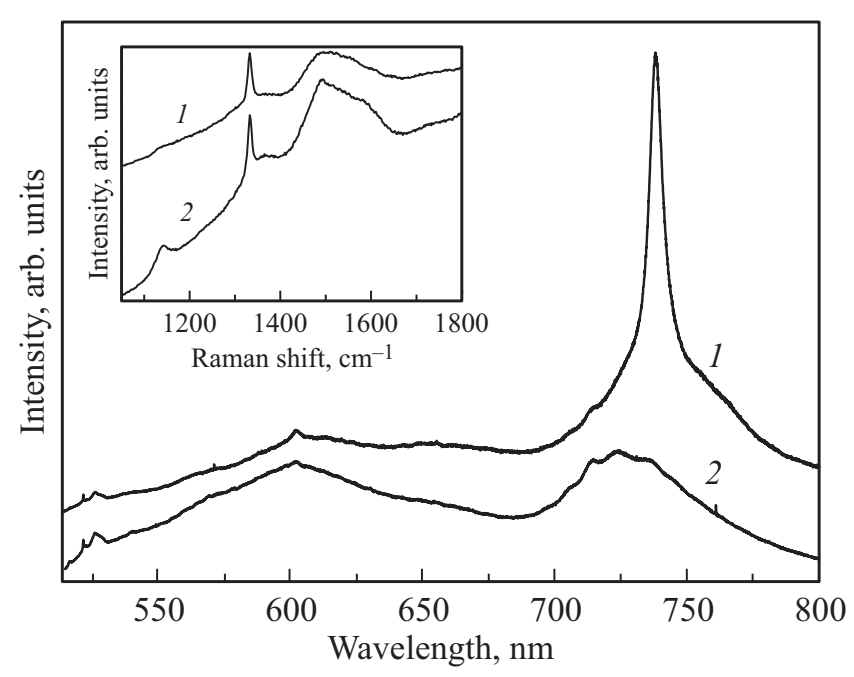

Pис. 1. Спектры ФЛ алмазных частиц на подложке кристаллического германия, полученные в присутствии (1) и в отсутствии (2) в процессе синтеза расположенной рядом с подложкой германия пластины кристаллического кремния. Температура поверхности подложки в процессе синтеза $830^{\circ} \mathrm{C}$. На вставке приведены спектры КРС.

широкая полоса ФЛ с максимумом в области $600 \mathrm{~nm}$. Слабая узкая линия $602.3 \mathrm{~nm}$ является БФЛ центра окраски $\mathrm{GeV}$ [16].

В спектре ФЛ алмазных частиц, синтезированных в отсутствии рядом с подложкой германия кремниевой пластины, наблюдается широкая полоса в диапазоне длин волн 670-800 nm (рис. 1, кривая 2). На огибающей контура эмиссии этой широкой полосы наблюдаются максимумы в области 714.4, 723.6, $734.4 \mathrm{~nm}$, которые в работах $[26,27]$ приписывают линиям излучения кластеров вакансий в алмазе. Другой причиной появления в спектре ФЛ этой широкой полосы может быть излучение оптического центра, в состав которого входит вольфрам (W-центр). Линии люминесценция W-центра ранее наблюдалась в алмазных пленках, полученных методом HFCVD с использованием вольфрамовой спирали [28] и методом химического осаждения из газовой фазы в дуговом разряде с применением вольфрамовых электродов [29]. Присутствие примеси вольфрама в алмазных пленках, полученных методом HFCVD, обнаружено в работе [30].

В спектре ФЛ алмазных частиц, синтезированных при размещении рядом с подложкой германия кремниевой пластины, на фоне широкой полосы в диапазоне длин волн 670-800 nm наблюдается интенсивная линия центра окраски $\mathrm{SiV}$ с максимумом БФЛ на длине волны $738.2 \mathrm{~nm}$ (рис. 1, кривая 1). Формирование центров $\mathrm{SiV}$ в алмазных частицах на подложке германия происходило за счет вхождения в решетку алмаза кремния, образовавшегося в результате травления кремниевой пластины атомарным водородом.
На вставке рис. 1 приведены спектры КРС алмазных частиц. В этих спектрах полоса $1332 \mathrm{~cm}^{-1}$ соответствует ТО-фонону симметрии $F_{2 g}$ в решетке алмаза и указывает на присутствие кристаллической алмазной фазы ( $s p^{3}$-гибридизованного углерода) [31]. FWHM в обоих спектрах составляет $\sim 10.5 \mathrm{~cm}^{-1}$. Линии с максимумами в области $1350 \mathrm{~cm}^{-1}$ (D-линия) и $1580 \mathrm{~cm}^{-1}$ (G-линия) обусловлены присутствием в алмазных частицах $s p^{2}$-гибридизованного углерода [32]. Линия в области $1490 \mathrm{~cm}^{-1}$ связана с присутствием аморфного углерода в алмазных частицах [31]. Появление линии $1150 \mathrm{~cm}^{-1}$ можно приписать углеродным цепочкам типа трансполиацетилена [31]. Отношение интегральной интенсивностей линии КРС алмаза к интенсивности линий, связанных с $s p^{2}$-гибридизированным углеродом, практически не зависит от нахождения рядом с подложкой германия кремниевой пластины.

Интенсивность БФЛ центров $\mathrm{GeV}$ меньше интенсивности БФЛ центров $\mathrm{SiV}$ и сравнима по интенсивности с линией КРС алмаза (рис. 1, кривая 1). Одной из возможных причин слабой интенсивности БФЛ центра $\mathrm{GeV}$ является низкая концентрация радикалов $\mathrm{GeH}_{x}$ в газовой фазе, образующихся в результате травления подложки германия. Это может быть связано с тем, что скорость травления атомарным водородом кристаллического германия значительно меньше, чем кремния [33].

Повышение концентрации радикалов $\mathrm{GeH}_{x}$ в газовой фазе может увеличить интенсивность БФЛ линии центров $\mathrm{GeV}$. Для этой цели рядом с подложкой германия (на расстоянии $\sim 0.5 \mathrm{~mm}$ ) была размещена пластина кристаллического германия толщиной $\sim 3 \mathrm{~mm}$ (размеры в латеральной плоскости $4 \times 2 \mathrm{~mm})$. Благодаря значительно большей толщине, чем у подложки германия, поверхность пластины германия располагается ближе к вольфрамовой спирали. Поэтому, из-за большого градиента температуры между вольфрамовой спиралью и держателем подложки поверхность пластины германия нагревается до температуры близкой к температуре плавления германия $\left(938^{\circ} \mathrm{C}\right)$. О достижении температуры плавления свидетельствуют характерные кратеры на поверхности пластины германия, не наблюдаемые на поверхности более тонкой подложке германия. При температуре поверхности близкой к температуре плавления на поверхности пластины германия происходит образование квазижидкого слоя, что может привести к более интенсивному ее травлению и увеличению образования летучих радикалов $\mathrm{GeH}_{x}$. Для проверки этого предположения был проведен синтез алмазных частиц на подложке германия при двух различных температурах поверхности подложки $660^{\circ} \mathrm{C}$ и $830^{\circ} \mathrm{C}$. На держателе подложек рядом с подложкой германия размещалась также пластина кремния.

На рис. 2 приведены спектры ФЛ алмазных частиц, синтезированных на подложке германия, когда рядом на держателе подложки дополнительно размещались пластины германия и кремния. Интенсивности спектров ФЛ нормированы на интенсивность линии $521.9 \mathrm{~nm}$ (линия 


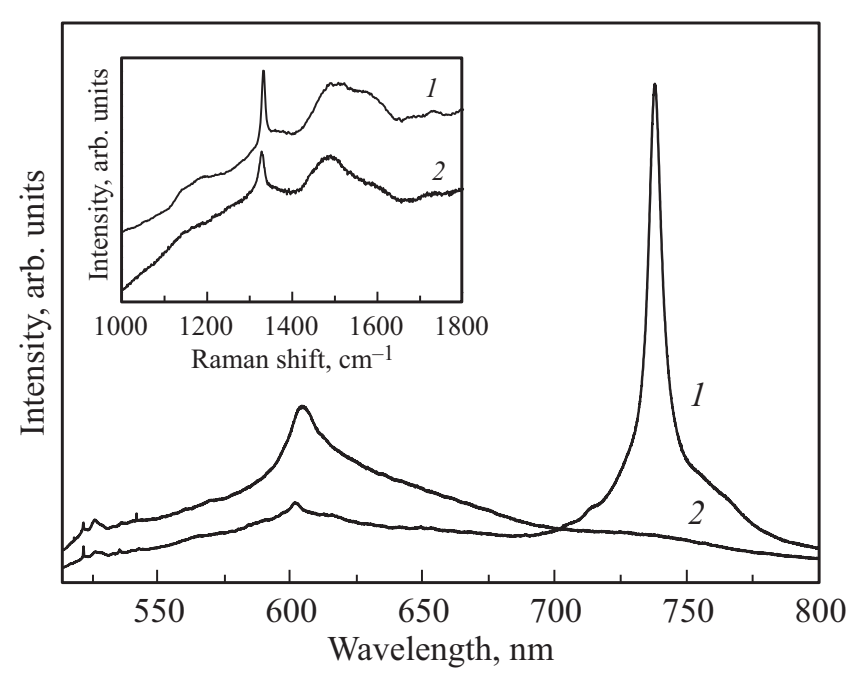

Pис. 2. Спектры ФЛ алмазных частиц на подложке кристаллического германия, синтезированных при размещении пластин германия и кремния рядом с подложкой германия. Температура подложки германия $830^{\circ} \mathrm{C}$ (1) и $660^{\circ} \mathrm{C}$ (2). На вставке приведены спектры КРС.

КРС алмаза на частоте $\left.\sim 1332 \mathrm{~cm}^{-1}\right)$. Интенсивность БФЛ центров $\mathrm{GeV}$ для алмазных частиц, синтезированных при температуре подложки $660^{\circ} \mathrm{C}$, выше, чем для частиц, синтезированных при температуре подложки $830^{\circ} \mathrm{C}$. Интенсивность линии БФЛ центров $\mathrm{GeV}$ для алмазных частиц, полученных при температуре подложки $830^{\circ} \mathrm{C}$, сравнима с интенсивностью ФЛ алмазных частиц, полученных в процессе HFCVD без размещенной рядом пластины германия (рис. 1, кривая 1). В спектре ФЛ алмазных частиц, полученных при температуре подложки $830^{\circ} \mathrm{C}$, присутствует БФЛ центра окраски $\mathrm{SiV}$, а при температуре $660^{\circ} \mathrm{C}$ данная линия не наблюдается.

На вставке рис. 2 показаны спектры КРС алмазных частиц, синтезированных при температуре 660 и $830^{\circ} \mathrm{C}$. Для алмазных частиц, полученных при температуре подложки $830^{\circ} \mathrm{C}$, линия КРС алмаза центрирована на $\sim 1332 \mathrm{~cm}^{-1}$ и FWHM равна $\sim 10 \mathrm{~cm}^{-1}$. Линия алмаза в спектре КРС алмазных частиц, полученных при температуре $660^{\circ} \mathrm{C}$, испытывает коротковолновый сдвиг до $\sim 1329.2 \mathrm{~cm}^{-1}$ относительно спектрального положения для объемного алмаза $\left(1332 \mathrm{~cm}^{-1}\right)$, а FWHM составляет $\sim 15 \mathrm{~cm}^{-1}$. Положение и ширина линии КРС алмаза, отношение интенсивности линии алмаза к линиям, обусловленным $s p^{2}$-гибридизованным углеродом, в обоих спектрах практически одинаковы.

На рис. 3 показаны спектры КРС алмазных частиц, образовавшихся на пластине кристаллического кремния. Кривая 1 соответствует спектру КРС алмазных частиц, полученных в том же HFCVD процессе, что и алмазные частицы на подложке германия, спектр ФЛ которых представлен на рис. 1 , кривая 1 . Кривая 2 соответствует спектру КРС алмазных частиц, полученных в том же HFCVD процессе, что и алмазные частицы на подложке германия, спектр ФЛ которых представлен на рис. 2, кривая 1 . Температура поверхности подложки кремния составляла $\sim 720^{\circ} \mathrm{C}$. В процессе синтеза рядом с пластиной кремния располагалась (кривая 2) или отсутствовала (кривая 1) пластина кристаллического германия. Спектры приведены в диапазоне частот, где регистрируются линии КPC на LO-фононах в кристаллическом германии $\left(300 \mathrm{~cm}^{-1}\right)$ и кристаллическом кремнии $\left(520 \mathrm{~cm}^{-1}\right)$. Линия КРС на частоте $300 \mathrm{~cm}^{-1}$ наблюдается в спектре алмазных частиц (рис. 3, кривая 2), полученных в присутствии рядом с подложкой германия дополнительной пластины германия. Наличие в спектре КРС алмазных частиц на пластине кремния линии на частоте $300 \mathrm{~cm}^{-1}$ свидетельствует о росте на ней кристаллического германия. Линия $300 \mathrm{~cm}^{-1}$ не наблюдается (рис. 3, кривая 1) в спектрах КРС алмазных частиц на пластине кремния, полученных в процессе HFCVD без пластины германия. Следовательно, пластина германия является более интенсивным источником $\mathrm{GeH}_{x}$, чем подложка германия. Возможно также, что размер кристаллитов германия очень мал и поэтому не обнаруживается в эксперименте по КРС. Из выше сказанного можно сделать вывод о том, что интенсивность травления пластины германия атомарным водородом значительно увеличивается при повышении температуры ее поверхности до температуры плавления.

На основе полученных экспериментальных результатов можно выдвинуть предположение, объясняющее различия в интенсивности БФЛ центра $\mathrm{GeV}$ в спектрах ФЛ алмазных частиц, синтезированных при температуре поверхности подложки германия 830 и $660^{\circ} \mathrm{C}$ (рис. 2).

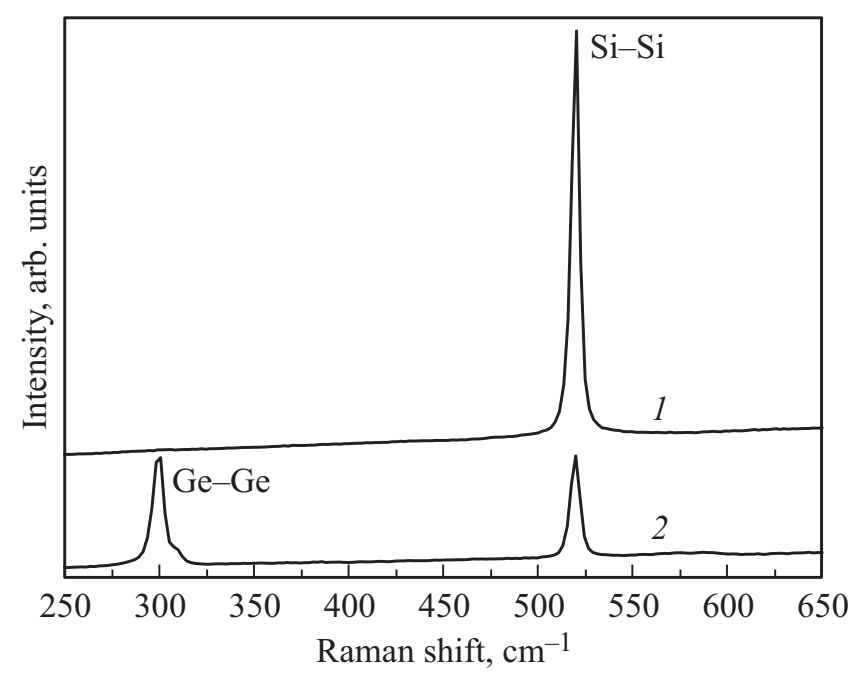

Рис. 3. Спектры КРС алмазных частиц, синтезированных методом HFCVD на пластине кремния. На держателе подложки рядом с пластиной кремния располагалась (кривая 2) или отсутствовала (кривая 1) пластина германия толщиной $\sim 3 \mathrm{~mm}$. 
При температуре $830^{\circ} \mathrm{C}$ подвижность осажденных радикалов (или атомов) германия на подложке достаточна, чтобы обеспечить рост кристаллитов германия. По-видимому, значительная доля атомов германия образует кристаллиты, а не участвует в образовании центров $\mathrm{GeV}$. Это обуславливает слабую интенсивность БФЛ центра $\mathrm{GeV}$. При температуре подложки германия $660^{\circ} \mathrm{C}$ замедляется миграция атомов германия по поверхности алмазных частиц. Вероятно, они менее эффективно образуют частицы кристаллического германия, и большая доля атомов германия становится доступна для образования центров $\mathrm{GeV}$. В результате в спектре ФЛ алмазных частиц наблюдается увеличение интенсивности БФЛ центров $\mathrm{GeV}$ (рис. 2, кривая 2). Наблюдаемый сдвиг в коротковолновую область и уширение КРС линии алмаза (рис. 2, кривая 2 на вставке) свидетельствуют об образовании алмазных кристаллитов размером в единицы нанометров [34]. Положение максимума БФЛ центров $\mathrm{GeV}$ в алмазных частицах, полученных при температуре $660^{\circ} \mathrm{C}$, составляет $604 \mathrm{~nm}$, то есть наблюдается длинноволновый сдвиг на $2 \mathrm{~nm}$ по отношению к ее положению в алмазах с микронным размером кристаллитов. Также наблюдается увеличение FWHM БФЛ центра $\mathrm{GeV}$ до $16 \mathrm{~nm}$.

Отсутствие БФЛ центра $\mathrm{SiV}$ в спектрах алмазных частиц на подложке германия, полученных при темпеpaтуре $660^{\circ} \mathrm{C}$ (рис. 2, кривая 2) можно связать с низкой температурой пластины кремния, при которой заметно уменьшается скорость травления пластины кремния атомарным водородом или с тем, что при данной температуре подложки германия сильно уменьшается вероятность образования центров окраски $\mathrm{SiV}$.

Таким образом, для достижения максимальной концентрации центров $\mathrm{GeV}$ в алмазных частицах необходимо обеспечить высокую концентрацию радикалов $\mathrm{GeH}_{x}$ в газовой фазе вблизи поверхности растущих алмазных частиц и высокую эффективность встраивания атомов германия в кристаллическую решетку алмаза с образованием оптического центра окраски. Можно предположить, что выполнение этих условий достигается при HFCVD синтезе алмазных частиц на подложке германия при температуре ее поверхности близкой к температуре плавления германия. При такой температуре интенсивное травление атомарным водородом с одной стороны приводит к высокой концентрации радикалов $\mathrm{GeH}_{x}$ и с другой стороны препятствует образованию кристаллитов германия на поверхности синтезируемых алмазных частиц.

Для подтверждения сделанного предположения был осуществлен синтез алмазных частиц на поверхности пластины германия толщиной $3 \mathrm{~mm}$ при температуре ее поверхности близкой к температуре плавления. Спектры ФЛ полученных алмазных частиц, измеренные при $T=300 \mathrm{~K}$ (кривая 1 ) и $T=80 \mathrm{~K}$ (кривая 2), приведены на рис. 4. При $T=300 \mathrm{~K}$ в спектре ФЛ алмазных частиц наблюдается интенсивная БФЛ центров $\mathrm{GeV}$ с максимумом на длине волны $602.2 \mathrm{~nm}$ и FWHM приблизительно

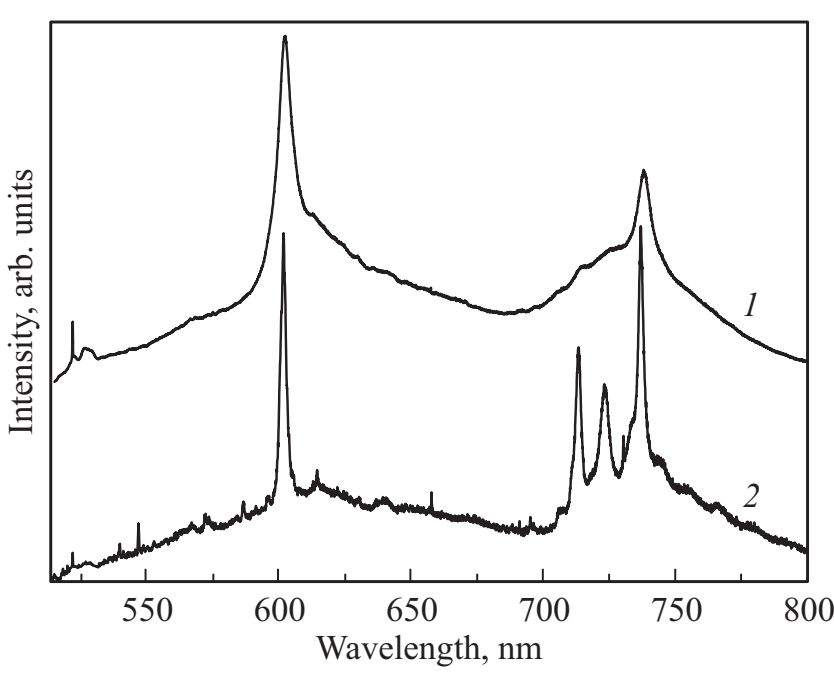

Рис. 4. Спектры ФЛ алмазных частиц на подложке германия толщиной $\sim 3 \mathrm{~mm}$, измеренные при $T=300 \mathrm{~K}(1)$ и $T=80 \mathrm{~K}(2)$. Температура поверхности подложки германия близка к температуре плавления германия.

равной $6.5 \mathrm{~nm}$. Интегральная интенсивность БФЛ центра $\mathrm{GeV}$ приблизительно в 200 раз выше интегральной интенсивности линии КРС алмаза (рис. 4).

В спектре ФЛ при $T=80 \mathrm{~K}$ максимум БФЛ центра $\mathrm{GeV}$ расположен на длине волны $601.8 \mathrm{~nm}$ и ее FWHM равна приблизительно $2.5 \mathrm{~nm}$. В спектрах на рис. 4 в области длин волн 670-800 nm наблюдаются линии возможное происхождение которых обсуждалось выше. Линии $738.1 \mathrm{~nm}$ при $T=300 \mathrm{~K}$ и $736.9 \mathrm{~nm}$ при $T=80 \mathrm{~K}$ являются БФЛ центра $\mathrm{SiV}$, появление которой мы связываем с наличием остаточного кремния на стенках и внутренних деталях реактора. FWHМ БФЛ центра $\mathrm{SiV}$ при $T=80 \mathrm{~K}$ составляет $\sim 2.2 \mathrm{~nm}$. В спектре ФЛ при $T=80 \mathrm{~K}$ наблюдаются две интенсивные узкие линии 713.2 и $723.3 \mathrm{~nm}$. Также в спектре на коротковолновом крыле БФЛ центра $\mathrm{SiV}$ наблюдается слабая линия $733.5 \mathrm{~nm}$, а на длинноволновом крыле БФЛ центра $\mathrm{SiV}$ наблюдаются слабые широкие линии 745.5, 755.3 и $766.2 \mathrm{~nm}$. По нашему мнению, более вероятной причиной происхождения этих линий является присутствие $\mathrm{W}$-центра в алмазных частицах. Особенность $\mathrm{W}$-центра состоит в наличии в спектре ФЛ в диапазоне длин волн от $704 \mathrm{~nm}$ до $713 \mathrm{~nm}$ пяти БФЛ, обозначаемых $\mathrm{W}_{1}-\mathrm{W}_{5}$ [29]. Наиболее интенсивной является БФЛ $\mathrm{W}_{5}$ [29], которую мы наблюдаем на длине волны $713.2 \mathrm{~nm}(1.738 \mathrm{eV})$. Линия $723.3 \mathrm{~nm}(1.714 \mathrm{eV})$ сдвинута в длинноволновую область спектра относительно БФЛ $\mathrm{W}_{5}$ на $\sim 24 \mathrm{meV}$. Спектральное расстояние между слабыми линиями 723.3, 733.5, 745.5, 755.3 и 766.2 также составляет $\sim 24 \mathrm{meV}$. Такое значение величины спектрального расстояния между наблюдаемыми линиями дает нам основание отнести эти линии к фононным повторениям БФЛ $\mathrm{W}_{5}$ [29]. 


\section{4. Заключение}

Методом HFCVD на подложке кристаллического германия синтезированы алмазные частицы с центрами окраски GeV. При комнатной температуре в спектрах ФЛ наблюдалась БФЛ центра окраски $\mathrm{GeV}$ на длине волны $\sim 602 \mathrm{~nm}$. Источником атомов германия являлись радикалы $\mathrm{GeH}_{x}$, образованные в результате травления кристаллического германия атомарным водородом. Слабая интенсивность БФЛ центра окраски $\mathrm{GeV}$ при температуре подложки германия $830^{\circ} \mathrm{C}$ связана с низкой концентрацией радикалов $\mathrm{GeH}_{x}$. Увеличение концентрации радикалов $\mathrm{GeH}_{x}$ достигнуто за счет размещения рядом с подложкой германия дополнительной пластины германия. В полученных при температуре поверхности подложки $660^{\circ} \mathrm{C}$ алмазных частицах, состоящих из кристаллитов нанометровых размеров, положение максимума БФЛ центров $\mathrm{GeV}$ испытывает длинноволновый сдвиг на $2 \mathrm{~nm}$ по отношению к ее положению в алмазах с микронным размером кристаллитов. Максимальная интенсивность БФЛ центра окраски $\mathrm{GeV}$ получена в алмазных частицах, выращенных на подложке германия толщиной $3 \mathrm{~mm}$ при температуре ее поверхности близкой к температуре плавления. В спектрах ФЛ алмазных частиц в области длин волн 780-800 nm наблюдались линии ФЛ, связанные, по-видимому, с присутствием в решетке алмаза оптических центров, в состав которых входит вольфрам.

\section{Финансирование работы}

Работа выполнена с использованием средств госбюджета по теме госзадания 0040-2019-0012.

\section{Конфликт интересов}

Авторы заявляют, что у них нет конфликта интересов.

\section{Список литературы}

[1] J.M. Smith, S.A. Meynell, A.C.B. Jayich, J. Meijer. Nanophotonics 8, 1889 (2019).

[2] T. Schröder, S.L. Mouradian, J. Zheng, M.E. Trusheim, M. Walsh, E.H. Chen, L. Li, I. Bayn, D. Englund. JOSA B 33, B65 (2016).

[3] I. Aharonovich, E. Neu. Adv. Opt. Mater. 2, 911 (2014).

[4] E. Neu. In: Nanodiamonds Advanced Material Analysis. Properties and Applications Elsevier / Ed. J.-C. Arnault. Elsevier. (2017). P. 419.

[5] O.A. Shenderova, A.I. Shames, N.A. Nunn, M.D. Torelli, I. Vlasov, A. Zaitsev. J. Vac. Sci. Technol. B 37, 030802 (2019).

[6] I. Aharonovich, S. Castelletto, D.A. Simpson, C.H. Su, A.D. Greentree, S. Prawer. Rep. Prog. Phys. 74, 076501 (2011).

[7] C. Bradac, W. Gao, J. Forneris, M. Trusheim, I. Aharonovich. arXiv1906.10992 (2019).
[8] E. Neu, M. Fische, S. Gsell, M. Schreck, C. Becher. Phys. Rev. B 84, 205211 (2011).

[9] I.I. Vlasov, A.S. Barnard, V.G. Ralchenko, O.I. Lebedev, M.V. Kanzyuba, A.V. Saveliev, V.I. Konov, E. Goovaerts. Adv. Mater. 21, 808 (2009).

[10] E. Neu, C. Arend, E. Gross, F. Guldner, C. Hepp, D. Steinmetz, E. Zscherpel, S. Ghodbane, H. Sternschulte, D. Steinmüller-Nethl, Y. Liang, A. Krueger, C. Becher. Appl. Phys. Lett. 98, 243107 (2011).

[11] A. Sipahigil, K.D. Jahnke, L.J. Rogers, T. Teraji, J. Isoya, A.S. Zibrov, F. Jelezko, M.D. Lukin. Phys. Rev. Lett. 113, 113602 (2014).

[12] M.K. Bhaskar, D.D. Sukachev, A. Sipahigil, R.E. Evans, M.J. Burek, C.T. Nguyen, L.J. Rogers, P. Siyushev, M.H. Metsch, H. Park, F. Jelezko, M.Lončar, M.D. Lukin. Phys. Rev. Lett. 118, 223603 (2017).

[13] T.T. Tran, B. Regan, E.A. Ekimov, Z. Mu, Y. Zhou, W. Gao, P. Narang, A.S. Solntsev, M. Toth, I. Aharonovich, C. Bradac. Sci. Adv. 5, eaav9180 (2019).

[14] K.D. Jahnke, A. Sipahigil, J.M. Binder, M.W. Doherty, M. Metsch, L.J. Rogers, N.B. Manson, M.D. Lukin, F. Jelezko. New J. Phys. 17, 043011 (2015).

[15] Y.N. Palyanov, I.N. Kupriyanov, Y.M. Borzdov, N.V. Surovtsev. Sci. Rep. 5, 14789 (2015).

[16] T. Iwasaki, F. Ishibashi, Y. Miyamoto, Y. Doi, S. Kobayashi, T. Miyazaki, K. Tahara, K.D. Jahnke, L.J. Rogers, B. Naydenov, F. Jelezko, S. Yamasaki, S. Nagamachi, T. Inubushi, N. Mizuochi, M. Hatano. Sci. Rep. 5, 12882 (2015).

[17] V. Sedov, A. Martyanov, S. Savin, A. Bolshakov, E. Bushuev, A. Khomich, O. Kudryavtsev, V. Krivobok, S. Nikolaev, V. Ralchenko. Diam. Rel. Mater. 90, 47 (2018).

[18] S. Pezzagna, D. Rogalla, D. Wildanger, J. Meijer, A. Zaitsev. New J. Phys. 13, 035024 (2011).

[19] E.A. Ekimov, M.V. Kondrin, V.S. Krivobok, A.A. Khomich, I.I. Vlasov, R.A. Khmelnitskiy, T. Iwasaki, M. Hatano. Diam. Rel. Mater. 93, 75 (2019).

[20] K.N. Boldyrev, B.N. Mavrin, P.S. Sherin, M.N. Popova. J. Lumin. 193, 119 (2018).

[21] S.A. Grudinkin, N.A. Feoktistov, A.V. Medvedev, K.V. Bogdanov, A.V. Baranov, A.Ya. Vul', V.G. Golubev. J. Phys. D 45, 062001 (2012).

[22] Н.А. Феоктистов, В.И. Сахаров, И.Т. Серенков, В.А. Толмачев, И.В. Коркин, А.Е. Алексенский, А.Я. Вуль, В.Г. Голубев. ЖТФ 81, 132 (2011).

[23] A.A. Basov, M. Rahn, M. Pars, I.I. Vlasov, I. Sildos, A.P. Bolshakov, V.G. Golubev, V.G. Ralchenko. Phys. Status Solidi A 206, 2009 (2009).

[24] S.A. Grudinkin, N.A. Feoktistov, M.A. Baranov, A.N. Smirnov, V.Y. Davydov, V.G. Golubev. Nanotechnol. 27, 395606 (2016).

[25] V.G. Ralchenko, V.S. Sedov, A.A. Khomich, V.S. Krivobok, S.N. Nikolaev, S.S. Savin, I.I. Vlasov, V.I. Konov. Bull. Lebedev Phys. Inst. 42, 165 (2015).

[26] S. Dannefaer, W. Zhu, T. Bretagnon, D. Kerr. Phys. Rev. B 53, 1979 (1996).

[27] D.V. Musale, S.R. Sainkar, S.T. Kshirsagar. Diam. Rel. Mater. 11, 75 (2002).

[28] J.W. Steeds, N.C. Burton, A.R. Lang, D. Pickard, Y.G. Shreter, J.E. Butler. Solid State Phenom. 51, 271 (1996). 
[29] S. Lal, T. Dallas, S. Yi, S. Gangopadhyay, M. Holtz, F.G. Anderson. Phys. Rev. B 54, 13428 (1996).

[30] P.M. Menon, A. Edwards, C.S. Feigerle, R.W. Shaw, D.W. Coffey, L. Heatherly, R.E. Clausing, L. Robinson, D.C. Glasgow. Diam. Rel. Mater. 8, 101 (1999).

[31] S. Prawer, R.J. Nemanich. Phil. Trans. R. Soc. Lond. A 362, 2537 (2004).

[32] K. Bogdanov, A. Fedorov, V. Osipov, T. Enoki, K. Takai, T. Hayashi, V. Ermakov, S. Moshkalev, A. Baranov. Carbon 73, 78 (2014).

[33] Y.J. Zheng, P.F. Ma, J.R. Engstrom. J. Appl. Phys. 90, 3614 (2001).

[34] А.Е. Алексенский, М.В. Байдакова, А.Я. Вуль, В.Ю. Давыдов, Ю.А. Певцова. ФТТ 39, 158 (1997).

Редактор К.В. Емиев 